\section{No catch to UK charity funding}

Universities receiving upwards of $£ 1$ billion (US $\$ 1$.6 billion) in total annually from UK medical research charities would probably disagree that their benefactors are 'hijacking' university resources

(Nature 481, 260; 2012).

The UK government supports charity-funded research as part of its higher-education funding. This enables charitable funds, often donated by the public, to be spent directly on research while the government pays universities to cover the costs of overheads and infrastructure.

Charities themselves invest in research infrastructure and resources. For example, the Wellcome Trust and Cancer Research UK are collaborating with the Medical Research Council and three London universities to invest $£ 650$ million in the Francis Crick Institute, a world-class research centre. The British Heart Foundation has committed $£ 10$ million to new university buildings since 2010, including $£ 1$ million towards the Centre for Regenerative Medicine at the University of Edinburgh.

The UK research base benefits from the breadth and diversity provided by a mix of public, forprofit and charitable funders. Mark Walport Wellcome Trust, London, UK. m.walport@wellcome.ac.uk Iain Foulkes Cancer Research UK, London, UK.

Peter Weissberg British Heart Foundation, London, UK. Delyth Morgan Breast Cancer Campaign, London, UK. Sharmila Nebhrajani Association of Medical Research Charities, London, UK.

\section{Whaling: don't trade the moratorium away}

In their proposal to allocate 'whale shares' to both whalers and conservationists as an alternative to the International
Whaling Commission (IWC) moratorium on commercial whaling, Christopher Costello and colleagues overlook several factors (Nature 481, 139-140; 2012).

Commercial whaling is in decline. In Japan, it is becoming less economically viable as consumer demand and whalemeat sales revenues fall - even with an increasing government subsidy, which this year is roughly $¥ 2.3$ billion (US $\$ 30$ million). Demand is also waning in Iceland and Norway. A ban on international trade prevents these countries from securing new markets. Last year, the global stockpile of unwanted whale meat reached more than 7,000 tonnes.

The effective management of commercial whaling would cost a lot more than its protagonists can afford and than non-whaling nations are willing to pay.

Costello et al. also overlook the high costs of the independent surveys and analysis that would be needed to generate safe quotas for whaling, as well as the international compliance scheme required to enforce regulations.

The IWC's founding treaty does not allow for quotas to be allocated to individual countries. Its renegotiation to facilitate a scheme such as Costello and colleagues describe would require unanimity, which is currently unthinkable. Given all this, it would be foolhardy to trade away the moratorium

Mark Peter Simmonds Whale and Dolphin Conservation Society, Chippenham, UK. mark.simmonds@wdcs.org Sue Fisher Animal Welfare Institute, Washington DC, USA.

\section{Whaling: ways to agree on quotas}

The sticking point in discussions of whale conservation schemes (Nature 481, 139-140; 2012) has been reaching agreement on the total catch that each whale population can sustain. The International Whaling Commission's scientific committee has developed and simulation-tested an adaptive algorithm, the Revised Management Procedure (RMP), to determine safe catch limits. For most populations, RMP limits are below the numbers discussed during the commission's failed 2010 negotiation of catch levels.

The whale-related expenditure of most of the organizations mentioned by Costello and colleagues goes largely to scientific research and outreach, not to protests. These funds have helped to develop tools such as the RMP, genetic techniques to monitor markets and improved methods for estimating whale numbers and demography.

If conservation organizations were to 'buy' whales, it would not necessarily reduce the numbers killed. Most catch quotas set by governments lie well above the numbers actually taken. Even if the more conservative RMP catch limits were applied to a new whale market, 'buying' a given number would not save that number over time. Under an adaptive-feedback management procedure such as the RMP, killing fewer whales one year tends to increase catch limits in subsequent years.

Justin G. Cooke Centre for Ecosystem Management Studies, Emmendingen, Germany. jgc@cems.de Russell Leaper University of Aberdeen, UK.

Vassili Papastavrou University of Bristol, UK.

\section{Big data deserve a bigger audience}

The huge repositories of data collected by services such as Twitter, Facebook and Google can cause serious problems beyond quality control (Nature 481, 25; 2012).

Many of the emerging 'big data' come from private sources that are inaccessible to other researchers. The data source may be hidden, compounding problems of verification, as well as concerns about the generality of the results.

These results are meaningful only if many other data sets reveal the same behaviour. This uncovers a deeper problem: if an independent set of data fails to validate results derived from privately owned data, how do we know whether it is because those data are not universal or because the authors made a mistake?

If this trend continues, we could see a small group of scientists with access to private data repositories enjoying an unfair amount of attention at the expense of equally talented researchers without these 'connections'.

Bernardo A. Huberman HP Labs, Palo Alto, California, USA.

bernardo.huberman@hp.com

\section{Data audits could curb misconduct}

Universities and government research institutes could perhaps learn from the private sector when it comes to curbing research misconduct (Nature 481, 237-238; 2012).

Research entities should undergo independent audits of scientific data annually by certified public scientists, in much the same way as businesses and not-for-profit organizations are independently audited by certified financial accountants (J. L. Glick Ann. NY Acad. Sci. 265, 178-192; 1976). Data audits are common for corporate biotechnology laboratories, but not for academic ones.

I estimated that the costs of funding questionable research practices (such as data misrepresentation and fabrication of results) could be reduced by US $\$ 5-10$ for each dollar spent on data audits (Account. Res. 2, 153-168; 1992). Besides being a cost-effective way of monitoring the integrity of research organizations, data auditing helps to reveal genuine errors. J. Leslie Glick Tampa, Florida, USA.jlglick@ix.netcom.com 